\title{
0 atual cenário do processo formativo de professores para o magistério da educação básica no Brasil
}

\section{The current scenario of the formation process of teachers for the teaching of basic education in Brazil}

\section{El escenario actual del proceso de formación de profesores para el magisterio de la educación básica en Brasil}

Rita Márcia Andrade Vaz de Mello, doutora em Educação pela Universidade Federal de Minas Gerais, com pós-doutorado em Educação pela UFMG e pela Sorbonne (Paris V), e professora associada da UFV. E-mail: ritamarciamello@gmail.com.

Carlos Roberto Jamil Cury, doutor em Educação pela Pontifícia Universidade Católica de São Paulo, com pós-doutorado pela Faculdade de Direito da Universidade de São Paulo, pela Sorbonne (Paris V), pela Escola de Altos Estudos em Ciências Sociais (EHESS), França, e pela Universidade Federal do Rio de Janeiro; professor emérito da UFMG e professor adjunto da Pontifícia Universidade Católica de Minas Gerais. E-mail: crjcury.bh@terra.com.br.

\section{Resumo}

No atual contexto brasileiro de formação de professores, destaca-se o Conselho Técnico-Científico de Educação Básica da Coordenação de Aperfeiçoamento de Pessoal de Nivel Superior (CTC-EB/Capes). A partir de diálogos com a literatura e a legislação educacional que tratam da formação inicial e continuada de professores e de questionários aplicados a membros do CTC-EB/Capes, esperamos oferecer subsídios tanto para a sua dinâmica quanto para a compreensão dessa formação e seu aperfeiçoamento. Ressaltamos o importante papel desse conselho na condução da Política Nacional de Formação de Professores. Evidencia-se a transitoriedade do nível de 
formação do professor, bem como o conflito entre o reconhecimento da necessidade de formação em nível superior e a manutenção dela em nível médio, o que denota a indefinição de uma política de formação desses profissionais.

Palavras-chave: Formação de Professores. Política Educacional. Educação Básica.

\section{Abstract}

In the current Brazilian context of teacher education, the Scientific Technical Council of Basic Education CAPES deserves to be highlighted. Through interaction with the literature and educational legislation dealing with the initial and continuing training of teachers and the application of questionnaires to members of the CTC/EB/ CAPES, we hope to contribute to the dynamics of the training and to understanding and improving it. We acknowledge the important role of the CTC/EB/CAPES in conducting the National Policy of Teacher Training. The study reveals the transitory nature of the level on which teacher training occurs. It also highlights the conflict between recognizing the need for training within higher education and keeping it on the secondary level, thereby denoting the indefinition of a training policy for these professionals.

Keywords: Teacher Education. Educational Policy. Basic Education.

\section{Resumen}

En el contexto brasileño actual de la formación docente, se destaca el Consejo Técnico Científico de la Educación Básica de la CAPES. De diálogos con la literatura y la legislación educativa que tratan de la formación inicial y continuada de los docentes y los cuestionarios aplicados a los miembros de la CTC/EB/CAPES, esperamos ofrecer subsidios tanto a su dinámica cuanto a la comprensión de esa formación y su perfeccionamiento. Señalamos el importante papel de la CTC/EB/ CAPES en la conducción de la Política Nacional de Formación Docente. Se destaca la fugacidad del nivel de formación de los docentes, el 
conflicto entre el reconocimiento de la necesidad de formación en la educación superior y en el mantenimiento de esta en el nivel secundario, lo que denota la indefinición de una política de formación de estos profesionales.

Palabras clave: Formación del Profesorado. Política Educativa. Educación Básica.

\section{Introdução}

Este trabalho objetiva refletir sobre a formação de professores no atual contexto brasileiro. Como procedimento metodológico de caráter teórico-descritivo, realizamos uma seleção de estudos para levantar os dilemas, as possibilidades e os desafios que têm sido apresentados à formação de professores, especialmente em nível de educação básica, nos últimos anos. A análise documental foi de suma importância para a análise das políticas educacionais, destacandose a atual configuração da Capes no que tange ao eixo referente à educação básica. Para compreendermos as possíveis repercussões que o modelo Capes de formação inicial e continuada, em especial no contexto das diretrizes de política de formação de docente, está trazendo para o contexto da educação básica, analisamos tanto os elementos quantitativos (tabelas e estatísticas oficiais) quanto os qualitativos (documentos de avaliação) e questionários com membros do primeiro e do atual Conselho Técnico-Científico da Educação Básica - Capes (CTC-EB/Capes).

Trabalhar com a temática de formação de professores no âmbito das políticas educacionais afigurou-se-nos um campo de pesquisa e de aprofundamento quando a "nova" Capes, instituindo uma Política Nacional de Formação Docente, erigiu, similarmente à Pós-Graduação, o CTC-EB como colegiado incumbido de gerir as diretrizes dessa política pública. E consideramos de fundamental importância, nesse processo, acompanhar e analisar essas diretrizes.

O atual Plano Nacional de Pós-Graduação (PNPG) traz, em um de seus cinco eixos, a meta de interação mais definitiva com a educação 
básica, como uma maneira de reforçar a aproximação do SNPG com os interesses da sociedade. Assim, coube a este estudo aprofundar a compreensão do CTC-EB/Capes e as diretrizes da política nacional de formação docente.

Diante do contexto exposto, levantamos a seguinte questão: quais têm sido as diretrizes propostas no interior da Política Nacional de Formação de Professores da educação básica tais como apresentadas pelo Conselho Técnico-Científico da Capes?

Para isso, pretendeu-se verificar como essas propostas se articulam com as sucessivas tendências expressas na literatura educacional, que vem se debruçando sobre o status quaestionis dessa formação.

De acordo com as reflexões feitas a partir de diálogos com a literatura e com a atual legislação educacional que tratam da formação inicial e continuada de professores da educação básica e de questionários aplicados a membros do Conselho Técnico Científico da Educação Básica, esperamos oferecer subsídios tanto para a dinâmica do CTC-EB/Capes quanto para a compreensão dessa formação e o seu aperfeiçoamento.

\section{Políticas nacionais de formação inicial e continuada de professores}

No Brasil, a formação de professores que atuam na educação básica tem sido objeto de reflexões, sobretudo a partir da década de 1990, com a aprovação da Lei de Diretrizes e Bases da Educação Nacional (Lei n 9.394/96), que estabeleceu as diretrizes e bases da educação nacional.

O Brasil é um Estado Federado em que cada ente - União, estados e municípios - tem obrigações específicas no que concerne à educação e à autonomia de políticas dentro da estrutura daquela lei, resultando daí um complexo de intercorrências no curso das políticas educacionais. 
Segundo Cury (2010), uma federação é a união de membros federados que formam uma só entidade soberana, que seria o Estado Nacional, na qual as unidades federadas subnacionais (estados e municípios, no caso brasileiro) gozam de autonomia dentro dos limites jurisdicionais atribuídos e especificados. De acordo com o autor (2010, p. 153), existem três modelos de federalismo: o federalismo centrípeto, que se caracteriza pelo fortalecimento do poder da União; o federalismo centrífugo, no qual há fortalecimento do poder dos estados-membros sobre o da União, com considerável autonomia daqueles; e o federalismo de cooperação, no qual se busca um equilíbrio de poderes entre a União e os estados-membros, estabelecendo laços de colaboração na distribuição das múltiplas competências por meio de atividades planejadas e articuladas entre si, objetivando fins comuns. A compreensão desse conjunto é tão fundamental quanto a das reformas educacionais e dos distintos contextos que as cercam.

O fato de se privilegiar a universidade como espaço dessa formação deve-seà importância de garantir aos docentes uma formação teórica sólida, estreitamente vinculada à pesquisa e relacionada às complexas tramas do cotidiano dos espaços educacionais. Além disso, a universidade abre possibilidades de intercâmbio e experiências com diversas áreas do conhecimento.

A aprovação das Diretrizes Curriculares Nacionais para o curso de Pedagogia (Resolução CNE/CP n 01, de 15 de maio de 2006) e dos demais atos regulamentadores da formação de professores mostra que as reformas ocorridas no campo da formação de professores posteriormente à aprovação da atual LDB parecem apenas confirmar o que já estava posto na realidade educacional brasileira.

No que tange à formação de professores, a Lei n 9.394/96, com a redação dada pela Lei $n^{\circ}$ 12.796/13, prevê em seu art. 62:

Art. 62. A formação de docentes para atuar na educação básica farse-á em nível superior, em curso de licenciatura, de graduação plena, em universidades e institutos superiores de educação, admitida, como formação mínima para o exercício do magistério na educação infantil e nos 5 (cinco) primeiros anos do ensino fundamental, a oferecida em nível médio na modalidade normal (BRASIL, 2013). 
Analisando a alteração do art. 62 que a Lei n 12.796/13 traz à LDB 9.394/96, é possível averiguar que ocorre apenas uma pequena mudança devido à implantação do ensino fundamental de nove anos, bem como continua a admitir como formação mínima aquela oferecida em nível médio, na modalidade normal, para o exercício do magistério na educação infantil e nos cinco primeiros anos do ensino fundamental.

Além de caber à União, pelo $\S 1^{\circ}$ do art. $8^{\circ}$ da LDB, “a coordenação da política nacional de educação, articulando os diferentes níveis e sistemas", agora essa coordenação ganhou um locus cujo prestígio na pós-graduação é inegável. A iniciativa de alargar o campo de atribuição da Capes, após 13 anos de aprovação da LDB, decorreu do acionamento de tal competência. Desse modo, a União definiu a Política Nacional de Formação de Profissionais do Magistério da Educação Básica por meio do Decreto $n^{\circ}$ 6.755, de 29 de janeiro de 2009, já dentro da Lei ${ }^{\circ}$ 11.502/07. Esta última redefiniu as funções da Capes, abrindo-a para a educação básica. Importa saber que a Capes é uma agência da União e, no caso da formação docente, tem competência concorrente com os estados.

As principais diretrizes dessa política são: formação de qualidade; valorização do magistério; integração entre pós-graduação / formação de professores/escola de educação básica; inovação educacional com base na ambiência psicossocial, na produção, na disseminação e, especialmente, no acesso ao conhecimento, e responsabilidade compartilhada entre os entes envolvidos (regime de colaboração Capes/IES/estados/municípios).

Paralelamente, uma política passou a ser delineada a partir do Decreto $n^{\circ}$ 6.094, de 24 de abril de 2007, que dispõe sobre a implantação do Plano de Metas Compromisso Todos pela Educação, pela União Federal, em regime de colaboração com os municípios, o Distrito Federal e os estados, e a participação das famílias e da comunidade, mediante programas e ações de assistência técnica e financeira, visando à mobilização social pela melhoria da qualidade da educação básica. 
Esse decreto disciplinou a adesão ao Plano de Metas Compromisso Todos pela Educação, que deu origem ao Termo de Cooperação entre o Ministério da Educação (MEC) e as redes públicas de educação básica dos municípios, dos estados e do Distrito Federal, prevendo apoio de assistência técnica ou financeira aos que a ele aderissem, definindo os seguintes eixos de ação: I - Gestão educacional; II - Formação de professores e dos profissionais de serviço e apoio escolar; III - Práticas pedagógicas e avaliação e IV - Infraestrutura física e recursos pedagógicos. Trata-se do Plano de Ações Articuladas (PAR).

Nesse sentido, ganha relevância a análise da redefinição da política de formação de professores, historicamente dispersa em várias políticas, programas e ações de diversas secretarias do Ministério da Educação (MEC). Assim, o Governo Federal vem implementando ações em busca de maior organicidade entre os diversos setores que compõem a estrutura do Ministério e os que a ele se vinculam diretamente. Tendo o Plano de Desenvolvimento Educacional (PDE) como norte das atuais ações institucionais, o MEC sinaliza claramente para um redimensionamento de sua atuação, ao destacar a articulação entre a educação básica e a superior, por meio da prioridade a ações e políticas em várias áreas, destacando-se, entre elas, a formação de professores para a educação básica.

O Decreto $n^{\circ}$ 6.094, de 24 de abril de 2007, dispõe sobre a implementação do Plano de Metas Compromisso Todos pela Educação pela União Federal em regime de colaboração com municípios, Distrito Federal e estados e da participação das famílias e da comunidade, mediante programas e ações de assistência técnica e financeira, visando à mobilização social pela melhoria da qualidade da educação básica. 0 Decreto $n^{\circ}$ 6.755, de 29 de janeiro de 2009, institui a Política Nacional de Formação de Profissionais do Magistério da Educação Básica e preconiza, no art. $3^{\circ}$, inciso VI, que a ampliação do número de docentes atuantes na educação básica pública ocorra "preferencialmente na modalidade presencial" em instituições públicas. Contudo, os dados nos revelam outra realidade. 
É válido destacar que o Conselho Nacional de Educação, ao tratar da educação superior, identifica o ensino a distância (EaD) como uma modalidade educacional e denota a sua presença no quadro da expansão da educação superior. O Conselho reconhece que "nos últimos quatro anos, de 2004 a 2008, o salto via EaD foi de $1.175 \%$, percentual extremamente diferenciado do relativo ao aumento de matrículas presenciais no mesmo período, que foi de apenas $17 \%$ " (BRASIL, 2009a, p. 46).

O regime de colaboração se encontra explícito, fazendo menção à cooperação mútua entre Capes, Secretarias de Educação e instituições públicas de ensino superior. No documento é anunciado o sistema eletrônico denominado Plataforma Freire, com vistas a reunir informações e gerenciar a participação nos cursos de formação inicial e continuada voltada para os professores da rede pública de ensino no âmbito do Plano Nacional de Formação de Professores da Educação Básica (Parfor).

As ações de formação de professores, em especial, facilitadas hoje na oferta via EaD, são fundamentais para os programas de formação pedagógica e para o cumprimento do disposto na atual LDB, conforme destacado por Teatini (2010):

A meta é diminuir o déficit de professores em exercício das escolas públicas estaduais e municipais que atuam sem formação adequada às exigências da Lei de Diretrizes e Bases da Educação Brasileira (LDB/1996). Trata-se, desse modo, de um esforço histórico inédito de articulação envolvendo as diferentes esferas responsáveis pela gestão de políticas públicas relacionadas à formação, num fim único, que é a melhoria da qualidade da educação brasileira (p. 146).

Os cursos de formação inicial de professores têm papel primordial na constituição dos saberes profissionais dos futuros docentes, e é por meio da relação com os professores formadores que os licenciados "[...] podem desmitificar e ressignificar determinadas informações e conhecimentos adquiridos em sua trajetória de alunos" (ANDRÉ; HOBOLD; PASSOS, 2012, p. 148). O desafio da formação inicial de professores é “[...] colaborar no processo de passagem da visão do 
aluno enquanto aluno para a visão dele mesmo enquanto professor" (FARIAS; MAGALHÃES, 2012, p. 258). Portanto, “a formação inicial do professor [...] deve ser a mais sólida e rigorosa possível, com a oferta de uma educação continuada” (CURY, 2009, p. 122).

Em artigo intitulado "Formação inicial de professores da educação básica no Brasil: trajetória e perspectivas”, Azevedo et al. (2012) fizeram uma breve trajetória histórica em relação à formação oferecida aos docentes no Brasil, desde as primeiras iniciativas até os dias de hoje, sendo que:

[...] nos anos 1960, havia o entendimento da docência como transmissão de conhecimento; nos anos 1970, como um fazer técnico; nos anos 1980, como mudança social, a constituição de estudantes críticos e responsáveis pela mudança social; nos anos 1990, a atividade pedagógica como espaço privilegiado para problematizar, significar e explorar os conteúdos teóricos; nos anos 2000, a educação científica para uma atividade pedagógica como espaço de pesquisa, reflexão, construção e produção de conhecimento, na busca por uma racionalidade prática (AZEVEDO et al., 2012, p. 1020).

Cury (2013) alerta para a dinâmica de transformação do funcionamento de um sistema educativo ao afirmar que:

A preparação formativa de docentes para atuar na educação escolar básica, de qualquer ponto de vista hoje existente, se revela estratégica para as diferentes concepções que embasam diferentes propostas. Governos, entidades empresariais e sindicais, associações profissionais, movimentos da sociedade civil e, sobretudo, entidades ligadas às instituições formadoras convergem na importância da educação escolar para uma presença atuante do cidadão em sua vida profissional e política. Certamente não seria de se esperar que de tantas instâncias diversas e diferentes viesse a se conseguir um consenso a priori (p. 1).

Gatti (2010), entre outras lacunas, destaca a falta de integração entre os conteúdos nos currículos dos cursos para uma formação que integre conhecimentos disciplinares, fundamentos educacionais e atividades didáticas. Revela também que os estágios obrigatórios carecem de planejamentos adequados junto aos sistemas de ensino escolares. 
É na formação inicial do professor que começa a qualidade da educação, segundo aponta o Relatório de Gestão 2009-2013, da Diretoria de Formação de Professores da Educação Básica (DEB). A partir desse pensamento, a DEB fomenta três programas importantes:

O primeiro, o Plano Nacional de Formação de Professores da Educação Básica - Parfor destina-se a professores que já atuam na rede pública, porém, sem a formação superior exigida pela Lei de Diretrizes e Bases da Educação Nacional; o segundo, o Programa Institucional de Bolsa de Iniciação à Docência-Pibid, alcança alunos de licenciaturas - professores ainda em formação; e o terceiro, o Programa de Consolidação das Licenciaturas - Prodocência, busca promover a melhoria e a inovação nas licenciaturas, inclusive incentivando a atualização dos professores que formam professores (CAPES, 2014, p.5).

Segundo Gatti, Barreto e André (2011), vários são os fatores que vêm prejudicando a formação inicial e continuada de professores no País, destacando-se o aviltamento salarial, a ausência de condições adequadas para o exercício da docência e a má qualidade da formação. É importante salientar que esses fatores podem ser motivos de desestímulo para o exercício da profissão e da própria desmotivação para buscar o aprimoramento profissional, bem como para a escolha do magistério como profissão futura.

Nóvoa (1995) pontua o processo histórico da profissionalização docente propondo um modelo de análise dividido em quatro etapas. A primeira está inserida no contexto do século XVIII, quando ocorre o enquadramento do professor como corpo profissional, e a educação deixa, então, de ser campo exclusivo de atuação dos religiosos, como os jesuítas no século XVII e início do XVIII. A segunda etapa engloba o final do século XVIII, quando já não é permitido ensinar sem a autorização do Estado, e o professor passa a ter direito exclusivo de intervenção na área da educação. A terceira etapa apresenta-se como decisiva para o processo de profissionalização, pois nessa época surgem as escolas normais, representando uma vitória para o professorado. Já a quarta e última etapa corresponde à tomada de consciência dos interesses dos docentes como grupo profissional e à adesão deste grupo às associações profissionais. 
Para Alarcão (2004), o professor é hoje fundamental para ajudar a navegar na sociedade da informação, que, por ser do conhecimento, necessita de aprendizagem e, por ser globalizante, requer a compreensão da identidade individual.

Libâneo, Oliveira e Toschi (2003) argumentam que a formação continuada é a garantia do desenvolvimento profissional permanente:

Ela se faz por meio do estudo, da reflexão, da discussão e da confrontação das experiências dos professores. É responsabilidade da instituição, mas também do próprio professor. O desenvolvimento pessoal requer que o professor tome para si a responsabilidade com a própria formação, no contexto da instituição escolar (p. 389).

Para a DEB (CAPES, 2014), a formação continuada - nela incluída a extensão - responde à necessidade contemporânea de pensar a formação profissional em um continuum que se estende ao longo da vida. Compactuamos com a visão da diretoria, afirmando que a educação continuada não decorre de um catálogo de cursos prontos, mas de uma concepção de desenvolvimento profissional do professor que leva em conta: (a) os problemas e os desafios da escola e do contexto onde ela está inserida; (b) a necessidade de acompanhar a inovação e a evolução associadas ao conhecimento, à ciência e à tecnologia; (c) o respeito ao protagonismo do professor e a um espaço-tempo que lhe permita refletir criticamente e aperfeiçoar sua prática e (d) o diálogo e a parceria com atores e instituições competentes, capazes de contribuir para alavancar novos patamares de qualidade ao complexo trabalho de gestão da sala de aula e da escola.

Nesse contexto, Nóvoa (2009) assevera a importância dos processos de aprendizagem compartilhada e da cultura colaborativa na construção do conhecimento profissional dos professores. Para esse autor, entender a escola como lugar da formação dos professores implica considerá-la como espaço da análise partilhada das práticas e de reflexão sobre o trabalho docente, e o exercício desse diálogo envolve regras e procedimentos que precisam ser aprendidos e exercitados nos cursos de formação. 
Tardif (2002) ressalta a questão dos "saberes, que não podem estar separados das outras dimensões do ensino, nem do estudo do trabalho docente". O saber dos professores é um saber social, pois ele é partilhado por um grupo de agentes; sua posse e utilização repousam sobre todo o sistema, o que vem garantir a sua legitimidade e orientar sua definição e utilização; seus objetos são práticas sociais.

Cabe destacar que o trabalho docente tem passado por diversas mudanças em decorrência das reformas educacionais iniciadas na última década do século XX, trazendo implicações diretas para a educação escolar. Surgem novas atribuições para a escola e, consequentemente, para os professores, os quais são impelidos a adaptar-se às constantes mudanças do mundo globalizado, recebendo cobranças tanto do Estado como da própria sociedade. A formação do profissional professor torna-se efetivamente cada vez mais relevante no processo educacional no século XXI, pois observa-se que a construção dos saberes passa a ser dominada por novas tecnologias, no espaço e no tempo. Denota-se a necessidade de o profissional da educação ter espírito aguçado e muita vontade para aprender, razão pela qual o processo de formação torna-se mais e mais veemente a fim de responder às demandas do mundo contemporâneo com competência e profissionalismo (HAMZE, 2014).

Na concepção sobre o ensinar e aprender na docência, não podemos negar os limites epistemológicos inerentes e específicos do processo de reflexão como desencadeadores da produção do saber pelo profissional professor, haja vista o dilema que se confronta entre a rotina e a reflexão que surge em sua prática cotidiana, podendo se constituir em um obstáculo, mediante as condições objetivas de trabalho.

Em consonância com a análise de Oliveira (2004), cabe destacar o avanço no que tange ao piso salarial profissional nacional para os profissionais do magistério público da educação básica, após sancionada a Lei $n^{\circ} 11.738$.

Apesar de o Supremo Tribunal Federal (STF) ter reconhecido, em abril de 2011, a constitucionalidade da Lei do Piso, é ilustrativo denotar 
que, no âmbito das políticas públicas, a aplicação do dispositivo legal que assegura esse piso salarial nacional é negada concretamente por vários estados da Federação, mesmo a despeito do fato de o piso ser bastante inferior às reivindicações da categoria.

A Resolução $n^{\circ}$ 7, de 26 de abril de 2012, do Ministério da Educação, traz os novos critérios de complementação do piso salarial aprovados pela Comissão Intergovernamental para Financiamento da Educação de Qualidade, composta por membros do MEC, do Conselho Nacional de Secretários de Educação (Consed) e da União Nacional dos Dirigentes Municipais de Educação (Undime). Essa resolução trata do uso de parcela dos recursos da complementação da União ao Fundo de Manutenção e Desenvolvimento da Educação Básica (Fundeb) para o pagamento integral do piso salarial dos profissionais da educação básica pública.

No que tange diretamente à política nacional de formação docente, é válido destacar as estratégias das metas 15 e 16 :

\footnotetext{
Meta 15: Garantir, em regime de colaboração entre a União, os Estados, o Distrito Federal e os Municípios, no prazo de 1 ano de vigência deste PNE, política nacional de formação dos profissionais da educação de que tratam os incisos I, II e III do caput do art. 61 da Lei n 9.394, de 20 de dezembro de 1996, assegurado que todos os professores e as professoras da educação básica possuam formação específica de nível superior, obtida em curso de licenciatura na área de conhecimento em que atuam.

Meta 16: Formar 50\% dos professores da educação básica em nivel de pós-graduação lato e stricto sensu, garantir a todos formação continuada em sua área de atuação, considerando as necessidades, demandas e contextualizações dos sistemas de ensino (BRASIL, 2011, p. 43-45).
}

No desenvolvimento de suas atividades de indução e fomento à formação de professores para a educação básica, a DEB trabalha em quatro linhas de ação: (a) formação inicial, (b) formação continuada e extensão, (c) formação associada à pesquisa e (d) divulgação científica. A sinergia e a interseção entre as linhas e os programas podem potencializar os resultados educacionais, modificando o quadro brasileiro com maior velocidade (CAPES, 2014). 
No entanto, se o tempo deixa suas marcas, continuam outras indagações decorrentes da formação docente, inicial ou continuada, presencial ou a distância, porque o que importa não é a modalidade formativa e, sim, a qualidade desta; sobretudo, questionamos a valorização desse profissional, assegurada em legislações que efetivamente se concretizem em avanços reais.

\section{A instituição do Conselho Técnico-Científico de Educação Básica da Capes no cenário da Política Nacional de Formação de Profissionais da Educação Básica}

O estudo sobre a política de formação dos profissionais da educação traz à baila a configuração da "nova Capes", bem como a discussão sobre o regime de colaboração no campo das políticas educacionais e sua relação no domínio das esferas de governo.

No contexto da Política Nacional de Formação de Profissionais do Magistério da Educação Básica da Capes, foi instituído o Plano Nacional de Formação dos Professores da Educação Básica (Parfor), por meio da Portaria Normativa n 9, de 30 de junho de 2009. Resultou esse plano de um conjunto de ações do Ministério da Educação (MEC), em colaboração com as Secretarias de Educação dos estados e municípios e as instituições públicas de educação superior neles sediadas, para ministrar cursos superiores gratuitos e de qualidade a professores em exercício das escolas públicas sem formação adequada à Lei de Diretrizes e Bases da Educação Nacional (LDB - Lei n 9394/96) ou que atuam fora da área de formação.

Cumprindo o Decreto $n^{\circ}$ 6.755, o MEC delegou à Coordenação de Aperfeiçoamento de Pessoal de Nível Superior a responsabilidade pela indução, fomento e avaliação dos cursos no âmbito do Parfor, ofertando licenciaturas das áreas de conhecimento da educação básica, nas modalidades presenciais e a distância. A Diretoria de Educação Básica Presencial, de acordo com a legislação, deverá fornecer o suporte técnico às Secretarias de Educação dos Estados e às IES formadoras para viabilizar a oferta de cursos e vagas, em atendimento à demanda 
dos professores da rede pública estadual e municipal de educação básica, sem formação adequada à LDB.

Segundo Clímaco et al. (2012), a Capes faz jus ao reconhecimento nacional e internacional, tendo em vista:

[...] sua atuação na indução, no fomento e na avaliação do Sistema Nacional de Pós-Graduação. Com a Lei n 11.502, de julho de 2007, a agência assumiu uma nova e desafiadora missão na educação básica: induzir e fomentar a formação inicial e continuada de profissionais de magistério e sua valorização em todos os níveis e todas as modalidades de ensino. Em apenas três anos, a "nova" Capes conduz ações importantes na área, com as instituições brasileiras de ensino superior e demais órgãos do Ministério da Educação (MEC), por meio de duas diretorias específicas: Educação Básica Presencial e Educação a Distância (p. 1).

A Diretoria de Educação Básica da Capes trabalha em articulação com outras diretorias, apoiando a extensão de ações tradicionalmente voltadas à pós-graduação, com vistas a alcançar a formação de professores para a educação básica. Assim é com o Programa de Apoio a Eventos no País (Paep), desenvolvido pela Diretoria de Programas e Bolsas no País (DPB). Programa tradicional da Capes, o Paep fomenta a realização de eventos científicos, tecnológicos, educacionais e culturais de curta duração - de abrangência local, estadual, regional, nacional e/ ou internacional -, promovidos por sociedades e entidades de áreas afins e programas de pós-graduação e pesquisa. Em 2007 foi lançado o Programa Institucional de Bolsas de Iniciação à Docência (Pibid). Com os objetivos de incentivar e valorizar o magistério e aprimorar o processo de formação inicial de docentes para a educação básica, esse programa tem contribuído para a integração entre teoria e prática e para a aproximação entre a universidade e as escolas básicas, valorizando as licenciaturas e envolvendo o docente da escola básica na formação do licenciando, reconhecendo, portanto, a escola também como locus de formação inicial.

A partir de 2010, o fomento foi estendido a eventos oriundos de programas de licenciatura, de Secretarias de Educação municipais e 
estaduais e de outras entidades educacionais, estimulando a inserção da educação básica nas políticas e nos programas da Capes, além de seu apoio à formação e à valorização de professores.

Segundo dados do Relatório de Gestão 2009-2013 da Diretoria de Formação de Professores da Educação Básica, em 2013, a DEB alcançou o número de 311 instituições parceiras, somados todos os programas sob sua responsabilidade; destas, 102 são federais, 41 estaduais, 18 municipais e 150 são comunitárias ou privadas.

Cabe apontar que, entre as atribuições da Coordenação Geral de Desenvolvimento de Conteúdo Curricular e de Modelos Experimentais, está a de apoiar o CTC-EB no acompanhamento da avaliação dos cursos de Pedagogia, Licenciatura e Normal Superior, nos processos de avaliação conduzidos pelo Inep. Nesse escopo, é válido destacar que pesquisas realizadas em diversos estados mostram a ineficácia dos cursos organizados conforme as Diretrizes Curriculares Nacionais para os Cursos de Pedagogia para formação de professores. Essas pesquisas revelam cursos totalmente fragmentados, com enorme dispersão de disciplinas e distantes da realidade de atuação profissional dos docentes que por eles estão sendo formados, o que pode comprometer em larga escala a qualidade da formação das crianças brasileiras. Esse novo cenário de avaliação que se propõe oferece, assim, subsídios significativos a essa importante agência na valorização da formação inicial e contínua de professores da educação básica em nosso país.

\section{O olhar dos pesquisadores e atores no cenário do Conselho Técnico- Científico de Educação Básica da Capes}

A Campanha Nacional de Aperfeiçoamento de Pessoal de Nivel Superior (atual Capes) foi criada em 11 de julho de 1951, com o objetivo de "assegurar a existência de pessoal especializado em quantidade e qualidade suficientes para atender às necessidades dos empreendimentos públicos e privados que visam ao desenvolvimento do país”. A Lei n 8.405, de 9 de janeiro de 1992, confere novo vigor à instituição ao autorizar o poder público a instituir a Capes como Fundação Pública. 
Com a criação do Conselho Nacional de Desenvolvimento Científico e Tecnológico (CNPq), instala-se uma política voltada para o campo científico; nesse setor, percebe-se intensa preocupação com a formação de recursos humanos para concretizar o ideal de sociedade moderna, tecnológica e cientificamente adequada aos parâmetros nacionais e internacionais de desenvolvimento.

Vale ressaltar as observações de Cury (2010) no que tange ao sistema de pós-graduação no Brasil:

O sistema de pós-graduação, desde a lei n.4.024/61 e o parecer CFE n. 977/65, cresceu, tornou-se complexo, grande, controlado e avaliado. Ele veio se constituindo como um sistema e como um sistema nacional com legislação pertinente. Junto com as finalidades maiores da pósgraduação, tais como a formação de um corpo docente solidamente preparado e que seja um corpo de pesquisadores de alto nível, ele também pretende que o avanço do conhecimento exerça papel significativo em prol do desenvolvimento nacional e em favor do crescimento da cidadania. Para tanto, houve uma decisiva atuação do Estado, que se impôs como incentivador desse sistema (p. 164).

Avançando mais na história da pós-graduação brasileira, cabe destacar o cenário atual da agência, conhecida atualmente como a "nova Capes".

A Lei $n^{\circ}$ 11.502, de 2007, aprovada por unanimidade no Congresso Nacional, modifica as competências e a estrutura organizacional da Fundação Coordenação de Aperfeiçoamento de Pessoal de Nivel Superior - Capes, alterando a lei que a constituiu - Lei $n^{\circ}$ 8.405, de 1992 - e a Lei $n^{\circ} 11.273$, de 2006, que autoriza a concessão de bolsas de estudo e de pesquisa a participantes de programas de formação inicial e continuada de professores para a educação básica.

Segundo o ex-Ministro da Educação Fernando Haddad, a Lei n 11.502/2007 cria uma "nova Capes", que subsidiará o MEC "na formulação de políticas e no desenvolvimento de atividades de suporte à formação de profissionais de magistério para a educação básica e superior e para o desenvolvimento científico e tecnológico do País" (HADDAD, 2008). 
A Capes assume as disposições do decreto por meio da criação de duas novas diretorias: a de Educação Básica Presencial (DEB) e a de Educação a Distância (DED). Esta última ficou a cargo da Universidade Aberta do Brasil (UAB), criada pelo Ministério da Educação em 2005, fundamentada na modalidade à distância e na sua operacionalização por intermédio das tecnologias da informação e comunicação (TICs).

As ações coordenadas pela agência culminaram com o lançamento do Plano Nacional de Formação dos Professores da Educação Básica, em 28 de maio de 2009. No contexto da Política Nacional de Formação de Profissionais do Magistério da Educação Básica, foi instituído, por meio da Portaria Normativa n ${ }^{\circ}$ 9, de 30 de junho de 2009, o Plano Nacional de Formação dos Professores da Educação Básica (Parfor), que se configura como o resultado de um conjunto de ações do Ministério da Educação (MEC), em colaboração com as Secretarias de Educação dos estados e municípios e as instituições públicas de educação superior neles sediadas, para ministrar cursos superiores gratuitos e de qualidade a professores em exercício das escolas públicas sem formação adequada à Lei de Diretrizes e Bases da Educação Nacional (LDB - Lei n 9394/96) ou que atuam fora da área de formação.

A assunção, pela Capes, desse importante segmento da educação nacional pauta-se em sua experiência histórica e metodológica, que se fez bem-sucedida na pós-graduação. Trata-se agora de recontextualizar essa metodologia no âmbito da educação básica. Posto isso, criou-se na Capes o Conselho Técnico-Científico da Educação Básica (CTC-EB), instituído no bojo da concepção do PDE, em 2007, que apresenta a seguinte composição: I - o presidente da Capes, que o presidirá; II - os secretários de Educação Básica, de Educação Superior, de Educação Profissional e Tecnológica, de Educação a Distância, de Educação Especial e de Educação Continuada, Alfabetização e Diversidade do Ministério da Educação; III - os diretores de Educação Básica Presencial, de Ensino a Distância, de Avaliação e de Relações Internacionais da Capes; IV - representantes da sociedade civil escolhidos entre profissionais de reconhecida competência em educação básica, observada a representatividade regional e por área de formação, quando possível. 
Visando a uma avaliação mais criteriosa, o MEC entendeu que a avaliação da educação básica deveria ser realizada pela Coordenação de Aperfeiçoamento de Pessoal de Nivel Superior, fato que originou a criação da nova Capes. Consideramos que o pressuposto do MEC seja o de que a avaliação da educação básica ganhe maior credibilidade e visibilidade, tomando como exemplo o reconhecimento nacional e internacional das avaliações realizadas por essa coordenação no que tange à pós-graduação.

A primeira composição do CTC-EB foi feita por consultas informais a diversas organizações que atuam na área da educação básica no Brasil, bem como por convites a educadores, pesquisadores e personalidades com reconhecida atuação nesse nível de ensino, sendo que 20 foram designados para compor o referido conselho, junto com seis secretários do MEC e cinco diretores da Capes.

Na esteira de Scheibe (2011), solicita-se desse conselho um apoio fundamental para que as diretorias da nova Capes - de Educação Básica Presencial e de Educação à Distância - e suas respectivas coordenações:

[...] possam implementar a tão necessária política de formação e de valorização profissional dos docentes da educação básica. Cabe, portanto, a este coletivo um trabalho novo, que exige criação, novos papéis, novas articulações e especialmente novas atribuições e responsabilidades. Sem dúvida, um trabalho difícil pela sua inovação no âmbito de uma instituição que vinha se responsabilizando pela formação dos profissionais para o ensino superior no país. Difícil também por ocupar um espaço e tempo de disputa de projetos com os quais convivemos no contexto atual. Mas, por isso mesmo, é tarefa desafiadora, sobretudo como espaço de interlocução com a área, com suas diversas entidades, sistemas educacionais e, particularmente, com as instituições de ensino superior responsáveis pela formação dos profissionais do magistério da educação básica (SCHEIBE, 2011, p. 7).

Importa destacar como alguns de seus membros entendem a importância e o papel desse conselho no contexto do cenário educacional brasileiro. Para isso, serão apresentados alguns trechos com a opinião de quatro respondentes dos questionários, membros do CTC-EB/Capes 
que participaram do presente estudo. Obviamente, por questões éticas, utilizaremos nomes fictícios.

Criar um CTC da Educação Básica na Capes se apresentou, inicialmente, como uma iniciativa promissora, que responderia à necessidade de estabelecimento de uma política de formação de professores para esse segmento da educação, em articulação com o CTC do Ensino Superior, já em funcionamento na Capes há muitos anos, e com as políticas do MEC (professora "A").

Tendo em vista esta nova atribuição, foram implantados na Capes, além de novas diretorias e coordenações, o Conselho Técnico Científico (CTC) da Educação Básica, com a finalidade de dar apoio e subsídios à instituição, enfatizando a implementação de uma política de formação e de valorização profissional dos docentes da Educação Básica. Sobre sua atuação, o então Ministro da Educação, Fernando Haddad, considerou que o papel do conselho é consultivo, com autoridade perante o MEC para recomendar e sugerir ações. O Ministro sugeriu também que o conselho tivesse como meta inicial duas questões importantes: o acesso ao sistema público de formação inicial e continuada, por meio das universidades federais; e a qualificação da oferta de formação inicial e continuada. Para tanto, afirmou a necessidade de criar o sistema nacional de formação de professores (professora “B”).

A professora "C" afirma: "O CTC-EB passou a ocupar posição central ao ser criado no contexto das políticas com visão sistêmica no campo da educação, objetivo central do PDE".

Acrescentando, o professor "D" declara que "sua constituição é um reconhecimento da importância da formulação de políticas do executivo para a educação básica”.

Constatamos que o CTC-EB constitui, formalmente, uma instância importante na articulação de políticas educacionais. A tarefa inicial indicada ao CTC foi a de construir um Sistema Nacional de Formação de Professores. O próprio Ministro da Educação trouxe essa temática para a Capes. O CTC da Educação Básica dedicou diversas reuniões à discussão do tema. Foram compostas câmaras de estudos para essa discussão, entre elas uma que analisou especificamente a questão da possibilidade de existência de um sistema nacional de formação de professores. 
A esse respeito, Ferreira (2011) adverte que os representantes do CTC da Educação Básica tinham a incumbência de criar um sistema nacional de formação e que isso não seria possivel enquanto não houvesse um sistema nacional de educação'. Foi, então, discutida pelo CTC da Educação Básica uma proposta de política para a formação dos professores no País, consoante o $\S 1^{\circ}$ do art. $8^{\circ}$ da LDB, que foi aprovada pelo Ministério da Educação e se tornou um decreto da Presidência da República sobre a Política Nacional de Formação de Profissionais do Magistério da Educação Básica.

Com relação ao papel do CTC-EB, os professores comentam:

O CTC/EB, se conseguir exercer suas atribuições, pode ter um papel relevante para a implementação do PNE, uma vez que esse inclui várias metas voltadas para a formação de professores, e metas bastante ambiciosas. O exercício desse papel dependerá de uma real articulação entre MEC, Capes e entidades federativas (professora “A”).

O CTC-EB deveria se ocupar em propor estratégias para que MEC e Capes pudessem construir pactos colaborativos entre os sistemas para que as metas fossem atingidas. Deveria também elaborar, em conjunto com o Inep, indicadores e formas de acompanhamento das metas nacionais relativas à formação docente (professora "C").

Se o peso do CTC-EB começar a se aproximar do peso do CTC-ES, em termos de efetiva elaboração de políticas e aplicação orientada de recursos, e se for estabelecida uma interface dinâmica com a Câmara de Educação Básica do CNE, será relevante seu papel para aproximar a formação de professores da escola básica, realidades hoje totalmente apartadas (professor “D”).

A opinião dos professores está em consonância com o papel da Capes no âmbito da educação básica no que tange ao Estatuto da instituição:

§ $2^{\circ}$ No âmbito da educação básica, a Capes terá como finalidade induzir e fomentar, inclusive em regime de colaboração com os estados, os municípios e o Distrito Federal e exclusivamente mediante convênios com instituições de ensino superior, a formação inicial e continuada de profissionais do magistério da educação básica, e, especialmente:

\footnotetext{
A Emenda Constitucional n 59/09 criou o Sistema Nacional de Educação. Sua consistência ainda depende de outra lei ordinária, tal como dispõe a Lei $n^{\circ}$ $13.005 / 14$, de acordo com o seu art. 13.
} 
I-fomentar programas de formação inicial e continuada de profissionais do magistério para a educação básica com vistas à construção de um sistema nacional de formação de professores;

II - articular políticas de formação de profissionais do magistério da educação básica em todos os níveis de governo, com base no regime de colaboração;

III - planejar ações de longo prazo para a formação inicial e continuada dos profissionais do magistério da educação básica em serviço;

IV - elaborar programas de atuação setorial ou regional, de forma a atender à demanda social por profissionais do magistério da educação básica;

V - acompanhar o desempenho dos cursos de licenciatura nas avaliações conduzidas pelo Instituto Nacional de Estudos e Pesquisas Educacionais Anísio Teixeira (INEP);

VI - promover e apoiar estudos e avaliações necessários ao desenvolvimento e melhoria de conteúdo e orientação curriculares dos cursos de formação inicial e continuada de profissionais de magistério; VII - manter intercâmbio com outros órgãos da administração pública do país, com organismos internacionais e com entidades privadas nacionais ou estrangeiras, visando promover a cooperação para o desenvolvimento da formação inicial e continuada de profissionais de magistério, mediante a celebração de convênios, acordos, contratos e ajustes que forem necessários à consecução de seus objetivos (CAPES, 2007, p. 8).

O papel do CTC-EB reforça a importância de a Capes ser a agência reguladora, a qual deverá discutir as diretrizes da formação, fixar os parâmetros para a avaliação dos cursos de Pedagogia, Licenciatura e Normal Superior, manifestar-se nos processos de reconhecimento e renovação dos cursos relacionados à formação, subsidiar a elaboração do Plano Nacional de Formação e opinar sobre os estudos e as pesquisas relativos aos conteúdos curriculares dos cursos (MAUÉS, 2008).

Scheibe (2012) destaca que, entre as competências do CTC-EB cumpridas ou que estiveram presentes em diversas pautas ao longo dos três anos de trabalho, "estão as discussões sobre diretrizes de longo prazo para a formação inicial e continuada dos professores do magistério da educação básica em serviço e a participação de seu representante no Conselho Superior". 
Compactuamos com a visão de Scheibe (2011) no que tange à composição de um Conselho Técnico-Científico da Educação Básica junto à Capes, ao ressaltar que o colegiado assume um papel de mediação entre a sociedade civil e os órgãos executivos da Capes no cumprimento da sua nova missão institucional, qual seja, a de sistematização e consolidação dos programas governamentais voltados para capacitação e formação inicial e continuada de profissionais do magistério da educação básica.

Os desafios postos enfatizam o importante papel da Capes na condução da Política Nacional de Formação de Professores, projetando o CTC-EB/Capes como grande potencializador de articulação e construção de tal política, de forma interinstitucional.

\section{Considerações finais}

Discutimos o estágio atual da Política Nacional de Formação dos Profissionais da Educação Básica, com o olhar para o plano legal, em especial, em face da "nova Capes". Como resultado das análises efetivadas e tomando por base as categorias empíricas, oriundas dos documentos oficiais e da revisão bibliográfica da temática, bem como a pesquisa de campo, consideramos que o presente estudo apontou a existência de uma forte relação de poder verticalizada entre os entes federados, advinda do passado, e a concepção de regime de colaboração posta na Constituição de 1988.

No âmbito da Política Nacional de Formação dos Profissionais do Magistério da Educação Básica, depreendemos que há relação de poder disposta no regime de colaboração, o que é confirmado pela Lei de Diretrizes e Bases. Essa relação está levando para as esferas mais distantes (os municípios), especialmente pelo Plano de Ações Articuladas (PAR), ações, entre estas a formação docente, a serem implantadas e implementadas pela União ou pelos estados.

Ao mesmo tempo, a nova configuração da Capes, voltada para a formação docente, tem peso maior no que concerne às instituições formadoras. 
Cabe ressaltar a participação da União no campo de valorização e formação dos profissionais docentes, com a aprovação de legislações normativas, como, por exemplo, o Fundo de Manutenção e Desenvolvimento do Ensino Básico e Valorização do Magistério (Lei $n^{\circ}$ 11.494, 2007); e a Lei $n^{\circ}$ 11.738, de 16 de julho de 2008, que instituiu o piso salarial profissional nacional para os profissionais do magistério público da educação básica, sendo acrescentada a esta novos recursos de repasse do Fundeb para complementação (Resolução $n^{\circ}$ 7, de 26 de abril de 2012). As leis recentemente aprovadas atribuem um papel fundamental ao Executivo Federal, que é o de ditar normas para a redefinição de responsabilidades no que diz respeito a oferta de ensino, avaliação, controle de qualidade e definição de padrões curriculares.

Denota-se que foram as medidas regulamentadas pelo Conselho Nacional de Educação (CNE), por intermédio de pareceres e resoluções, que deram o tom da reforma no campo da educação e da formação de professores no Brasil.

A Política Nacional de Formação de Professores da Educação Básica objetivou equalizar nacionalmente as oportunidades de formação inicial e continuada dos profissionais do magistério, assegurando a todos os professores em efetivo exercício sem curso superior ou que atuam fora da sua área de formação uma vaga gratuita em universidade. Destaca-se o papel ampliado da nova Capes, que passa a desenvolver diversas ações, de acordo com nova missão. Foram implementados programas que visam contribuir para o aprimoramento da qualidade da educação básica e estimular experiências inovadoras e o uso de recursos e tecnologias de comunicação e informação nas modalidades de educação presencial e a distância.

Vale enfatizar o importante papel do CTC-EB/Capes na condução da Política Nacional de Formação de Professores. A formação permanente de professores é fundamental para o desenvolvimento não somente do processo educativo, mas do próprio país, devendo concretamente ser um direito do professor uma exigência profissional que requer condições de inserção nos programas de formação continuada, bem como recursos necessários e incentivos salariais. 
Cabe ao CTC-EB, considerando a Capes como órgão de fomento a programas de formação inicial e continuada, a adoção de medidas que visam atacar os pontos frágeis que possam comprometer a qualidade da política de formação, como, por exemplo, alguns citados por Ferro (2013): revisão dos planos estratégicos dos estados; aprimoramento dos dados do Educacenso, garantindo uma visão mais precisa da realidade; consolidação dos fóruns e definição de diretrizes normativas para fortalecer suas ações e ampliar a interação com as instituições parceiras; fomento a projetos pedagógicos que proponham inovação nas matrizes curriculares e percursos formativos; e propostas de revisão da estrutura acadêmica e curricular dos cursos de licenciatura e pesquisas que impactem a formação de docentes.

É válido reiterar que a qualidade da educação e da formação de professores tem relação direta com o estabelecimento e a implementação de políticas educacionais que valorizem o magistério, contemplando igualmente a formação inicial e continuada do professor e sua melhor remuneração. Essas são as condições fundamentais para se proporcionar um ensino de qualidade, o acesso e a permanência dos alunos na escola, tornando-a, de fato, democrática. As IES são agências de fomento desse modelo de formação de professores, visto que são consideradas o braço forte do Estado na consolidação das políticas públicas de educação.

Ressalta-se o importante papel da nova Capes no que se refere à formação de professores para a educação básica, que passa a receber um novo tratamento no contexto das políticas públicas.

As questões postas neste estudo denotam que há demanda emergencial por professores com formação adequada, fato que impõe a necessidade de estratégias políticas que resolvam tal problema, mas é preocupante, porque uma política orgânica de Estado não pode se voltar para ajustes contingenciais; ao contrário, deve projetar ações que possam ser viabilizadas concretamente, bem como construir novos referenciais que conduzam à transformação da realidade educacional. 


\section{Referências}

ALARCÃO, I. Professores reflexivos em uma escola reflexiva. São Paulo: Cortez, 2004.

ANDRÉ, M. E. D. A.; HOBOLD, M. S.; PASSOS, L. F. Saberes docentes e representações sociais: aproximações. In: PLACCO, V. M. N. de S.; BÔAS, L. P. S. V.; SOUZA, C. P. (Org.). Representações sociais: diálogos com a educação. Curitiba: Champagnat; São Paulo: Fundação Carlos Chagas, 2012. p. 137-155.

AZEVEDO, R. O. M. et al. Formação inicial de professores da educação básica no Brasil: trajetória e perspectivas. Revista Diálogo Educacional, Curitiba, v. 12, n. 37, p. 997-1026, set./dez. 2012.

BARRETTO, E. S. S. Trabalho docente e modelos de formação: velhos e novos embates e representações. In: DALBEN, A.; DINIZ, J.; LEAL, L.; SANTOS, L. (Org.). Coleção didática e prática de ensino: convergências e tensões no campo da formação e do trabalho docente. Belo Horizonte: Autêntica, 2010. p. 288-306.

BRASIL. Congresso Nacional. Lei de Diretrizes e Bases da Educação Nacional. Diário Oficial [da] República Federativa do Brasil. Brasília, DF, 26 dez. 1996.

Constituição (1988). Constituição da República Federativa do

Brasil. Brasília, DF: Senado Federal: Centro Gráfico, 1988. 292 p.

. Decreto $n^{\circ}$ 6.755, de 29 de janeiro de 2009. Institui a Política Nacional de Formação de Profissionais do Magistério da Educação Básica, disciplina a atuação da Coordenação de Aperfeiçoamento de Pessoal de Nivel Superior - Capes no fomento a programas de formação inicial e continuada, e dá outras providências. Diário Oficial [da] República Federativa do Brasil, Poder Executivo, Brasília, DF, 30 jan. 2009. Seção 1, p.1-2. 
. Lei n ${ }^{\circ}$ 8.405, de 9 de janeiro de 1992. Autoriza o Poder Executivo a instituir como fundação pública a Coordenação de Aperfeiçoamento de Pessoal de Nível Superior (Capes) e dá outras providências. Diário Oficial [da] República Federativa do Brasil, Poder Executivo, Brasília, DF, 10 jan. 1992.

Lei $\mathrm{n}^{\circ}$ 11.502, de 11 de julho de 2007. Modifica as competências e a estrutura organizacional da fundação Coordenação de Aperfeiçoamento de Pessoal de Nível Superior - Capes. Brasília, DF: Congresso Nacional, 2008.

Lei $\mathrm{n}^{\circ} \mathbf{1 1 . 7 3 8}$, de 16 de julho de 2008. Regulamenta a alínea e do inciso III do caput do art. 60 do Ato das Disposições Constitucionais Transitórias, para instituir o piso salarial profissional nacional para os profissionais do magistério público da educação básica. Brasília, DF: Congresso Nacional, 2008.

Lei $\mathbf{n}^{\circ} \mathbf{1 2 . 7 9 6}$, de $\mathbf{4}$ de abril de 2013. Altera a Lei $\mathrm{n}$ 0 9.394, de 20 de dezembro de 1996, que estabelece as diretrizes e bases da educação nacional, para dispor sobre a formação dos profissionais da educação e dar outras providências. Brasília, DF: Congresso Nacional, 2013.

Ministério da Educação, Secretaria de Educação Superior, Coordenação de Aperfeiçoamento de Pessoal de Nível Superior. V Plano Nacional de Pós-Graduação, Brasília, DF: Departamento de Documentação e Divulgação, 2011.

Ministério da Educação. O Plano de Desenvolvimento da Educação. Razões, princípios e programas. Brasília, DF: MEC, 2007.

Ministério da Educação. Portaria Normativa $\mathbf{n}^{\circ}$ 9, de 30 de junho de 2009. Institui o Plano Nacional de Formação dos Professores da Educação Básica no âmbito do Ministério da Educação. Brasília, DF: MEC, 2009.

Ministério da Educação. Portaria Normativa $n^{\circ}$ 1328, de 23 de setembro de 2011. Institui a Rede Nacional de Formação Continuada 
dos profissionais do Magistério da Educação Básica no âmbito do Ministério da Educação. Brasília, DF: MEC, 2011.

Ministério da Educação. Projeto de Lei $\mathbf{n}^{\circ} \mathbf{8 . 0 3 5}$, de 15 de dezembro de 2010. Institui a Proposta Governamental de Plano Nacional de Formação dos Professores da Educação Básica (20112020) no âmbito do Ministério da Educação. Brasília, DF: MEC, 2010.

Projeto de Lei do Plano Nacional de Educação (PNE 2011/2020): projeto em tramitação no Congresso Nacional / PL n 8.035/2010/ organização: Márcia Abreu e Marcos Cordiolli. Brasília: Câmara dos Deputados, Edições Câmara, 2011.

CAPES - Coordenação de Aperfeiçoamento de Pessoal de Nível Superior. Sistema Nacional Público de Formação dos Profissionais do Magistério - Sugestões recebidas da Consulta Pública. Brasília, DF: Capes, 2007.

Relatório de Gestão 2009-2013, Diretoria de Formação de Professores da Educação Básica - DEB. Brasília, DF: Capes, 2014

CLÍMACO, J. C. T. S. et al. Ações da Capes para a formação e a valorização dos professores da educação básica do Brasil e sua interação com a pós-graduação. RBPG, Brasília, v. 9, n. 16, p. 181-209, abr. 2012.

CURY, C. R. J. A educação como desafio na ordem jurídica. In: LOPES, E. M. T.; FILHO, L. M. de F.; VEIGA, C.A. G. (Org.). 500 anos de educação no Brasil. 5. ed. Belo Horizonte: Autêntica, 2011.

A formação docente e a educação nacional. Disponível em: <http//portal.mec.gov.br/cne/arquivos/pdf/conselheiro.pdf>. Acesso em: 7 dez. 2013.

A questão federativa e a educação escolar. In: OLIVEIRA, R. P.; SANTANA, W. (Org.). Educação e federalismo no Brasil: combater as desigualdades, garantir a diversidade. Brasília: Unesco, 2010. 
Políticas públicas de educação e desigualdade. Disponível em: <http:/ / www.uab.ufjf.br/mod/resource/view.php?id=80554>. Acesso em: 12 out. 2012.

Potencialidades e limitações da certificação de professores.

Revista Retratos da Escola, Brasília, v. 3, n. 4, p. 117-134, jan. /jun. 2009.

FARIAS, M. L. S. O.; MAGALHÃES, P. M. M. S. Representações sociais sobre o afeto do aluno: um estilo no ensinar e aprender. In: PLACCO, V. M. N. de S.; BÔAS, L. P. S. V.; SOUZA, C. P. (Org.). Representações sociais: diálogos com a educação. Curitiba: Champagnat; São Paulo: Fundação Carlos Chagas, 2012. p. 249-273.

FERREIRA, D. L. A Organização para Cooperação e Desenvolvimento Econômico (OCDE) e a política de formação docente no Brasil. Belém, PA, 2011.

FERRO, M. G. D. O Plano Nacional de Formação de Professores da Educação Básica (PARFOR) no âmbito da UFPI: realidade, perspectivas e desafios de um percurso em construção. Disponível em: <http:// www.ufpi.br/subsiteFiles/parfor/arquivos/files/pdf>. Acesso em: 2 fev. 2013.

GATTI, B. A. Formação de professores no Brasil: características e problemas. Educ. Soc., Campinas, v. 31, n. 113, p. 1355-1379, out./dez. 2010.

GATTI, B. A.; BARRETO, E. S. S.; ANDRÉ, M. E. D. A. Políticas docentes no Brasil: um estado da arte. Brasília, DF: UNESCO, 2011.

HADDAD, S. (Org.). Banco Mundial, OMC e FMI: O impacto nas políticas educacionais. São Paulo: Cortez, 2008.

HAMZE, A. Governabilidade e governança. Disponível em: <http:// educador.brasilescola.com/política-educacional/governabilidadegovernança.htm. Em cache - Similares>. Acesso em: 12 set. 2014. 
LIBÂNEO, J. C.; OLIVEIRA, J. F.; TOSCHI, M. S. Educação escolar: políticas, estruturas e organização. São Paulo: Cortez, 2003.

MAUÉS, O. As políticas de formação e a pedagogia das competências. In: REUNIÃO ANUAL DA ANPED, 31., 2008, Caxambu. Anais eletrônicos... Caxambu: 2008.

NÓVOA, A. Profissão professor. 2 ed. Portugal: Porto Editora, 1995.

Professores: Imagens do futuro presente. Lisboa: Educa, 2009.

OLIVEIRA, D. A. A reestruturação do trabalho docente: precarização e flexibilização. Educ. Soc., Campinas, v. 25, n. 89, p. 1127-1144, set./dez. 2004.

SCHEIBE, L. O conselho técnico-científico da educação básica da Capes e a formação docente. Cad. Pesquisa, São Paulo, v. 41, n. 144, set./dez. 2011.

Políticas de Formação e o Sistema Nacional de Educação o protagonismo do CTC/Capes da educação básica. In: ENCONTRO NACIONAL DE DIDÁTICAS E PRÁTICAS DE ENSINO - ENDIPE. 16., 2012, Campinas. Anais... Campinas: Unicamp, 2012.

TARDIF, M. Saberes docentes e formação profissional. Petrópolis, RJ: Vozes, 2002.

TEATINI, J. C. Entrevista com o professor João Carlos Teatini. Revista Eletrônica Pesquiseduca, Santos, v. 2, n. 3, p. 145-147, jan./jun. 2010. 